\title{
Trace element-gene interactions with particular reference to zinc
}

\author{
BY JOHN K. CHESTERS \\ Rowett Research Institute, Bucksburn, Aberdeen AB2 9SB
}

\begin{abstract}
Review of situations in which trace elements are known to be involved in the functional expression of genes suggested that in most instances the element in question was zinc. However, transcriptional regulation by trace elements might be most likely for those proteins which are directly involved in uptake and storage of the elements and must, therefore, be responsive to variations in their supply. The regulation of certain of these proteins will, therefore, be considered before the wider involvement of $\mathrm{Zn}$ in gene regulation is examined.
\end{abstract}

\section{TRANSPORT AND STORAGE PROTEINS}

Two proteins are primarily involved in regulating the intracellular concentration of iron, ferritin and the receptor (TfR) for the Fe-transport protein transferrin. Changes in $\mathrm{Fe}$ supply produce a coordinated response in TfR and ferritin but this is achieved translationally rather than by controlling gene expression (Klausner \& Harford, 1989). Their mRNA contain Fe-responsive elements (IRE) that form stem-loop structures to which binds an Fe-dependent protein (IRE-BP). This has high affinity for IRE when Fe is scarce but low affinity when it is abundant. In ferritin mRNA, an IRE is located in the $5^{\prime}$ untranslated region and binding of IRE-BP inhibits translation of ferritin mRNA. In TfR mRNA, the IRE are located in the $3^{\prime}$ untranslated region and binding of IRE-BP stabilizes the mRNA allowing more efficient production of $\mathrm{TfR}$. Thus, at low $\mathrm{Fe}$ abundance, little ferritin but relatively large quantities of $T f R$ are produced. If Fe supply is abundant, these effects are reversed as the affinity of IRE-BP for IRE is decreased and this stimulates ferritin production while reducing the stability of TfR mRNA.

Caeruloplasmin has been suggested as a transport protein for copper (Harris \& Stevens, 1985) and there are indications that its mRNA concentration is regulated by dietary Cu content (Evans et al. 1970; Danks \& Mercer, 1988) but there is little definite evidence as yet regarding either the mechanism or extent of such regulation.

Selenium incorporation into proteins is determined genetically by a unique use of the codon UGA (Chambers \& Harrison, 1987). Normally treated as a stop codon during mRNA translation, it is used in selenoproteins to code for selenocysteine. The incorporation of this amino acid is mediated by an unusual tRNA initially charged with a serine residue which is then converted to selenocysteine while still attached to the tRNA (Leinfelder et al. 1990). The mechanism which distinguishes the two interpretations of UGA remains unknown but is assumed to depend on the local environment of the codon within its mRNA. The most extensively studied selenoprotein in animals is glutathione peroxidase (EC 1.11.1.9; GSHPX) and its activity can be influenced by dietary Se supply. Two reports have indicated that Se deficiency resulted in a reduction in GSHPx mRNA (Saedi et al. 1988; Toyoda et al. 1989) but a third suggested that it was elevated (Li et al. 1990). Clearly, further work is required to resolve these apparent contradictions.

Metallothionein is a small cysteine-rich protein which binds many divalent cations and 
probably acts as a storage protein for $\mathrm{Zn}$. $\mathrm{Zn}$ is a potent inducer of the protein and its promoter contains several closely-related nucleotide sequences, the metal-responsive elements (MRE), which confer sensitivity to metals and are capable of inducing similar sensitivity when introduced into promoters of other unrelated genes (Stuart et al. 1984). The activity of MRE is largely independent of their position within the promoter and they can even activate genes from a $3^{\prime}$ location. Gel-retardation assays and protein blotting with nucleotides containing a concensus sequence for the MRE, demonstrated a nuclear protein(s) which binds to the MRE (Seguin \& Prevost, 1988; Westin \& Schaffner, 1988a). Competition with oligonucleotides or plasmids containing MRE indicated that the protein acts as a metal-dependent activator of metallothionein transcription (Seguin et al. 1984; Garg et al. 1989). The most active of the mouse MRE exhibits a close homology between its $3^{\prime}$ zone and the consensus sequence required for promoter binding of $\mathrm{Sp1}$, a transcription factor known to activate many mammalian genes. While further competition experiments seem to have excluded the possibility that the MRE-binding protein is Sp1 (Seguin \& Prevost, 1988; Westin \& Schaffner, 1988a), the similarities are intriguing and will be considered further later.

\section{'ZN-FINGER' PROTEINS}

In addition to regulating metallothionein induction, $\mathrm{Zn}$ is also involved in the control of many other genes through its essential role in the so-called ' $Z n$-finger' proteins. The first of these to be recognized was a transcription factor TFIIIA necessary for the synthesis of 5S rRNA by RNA polymerase III (EC 2.7.7.6) (Hanas et al. 1983; Klug \& Rhodes, 1987). This was found to contain nine tandem imperfect repeats of a motif containing pairs of cysteine and histidine residues separated by twelve amino acids. These repeats contain one $\mathrm{Zn}$ tetrahedrally coordinated by the cysteine and histidine residues and the intervening residues were thought to form loops or finger-like structures which interacted with the 5S rRNA gene. Since the original description of this structure, numerous other proteins have been suggested to contain $\mathrm{Zn}$ fingers, often entirely on the basis of their deduced primary amino acid sequence, until the numbers of such proteins probably now exceed the number of known $\mathrm{Zn}$ enzymes. However, increasing information regarding these proteins has led to their provisional re-classification into three separate groups (Evans \& Hollenberg, 1988).

The first, exemplified by TFIIIA, have the characteristic two cysteines and two histidines per 'finger' $(\mathrm{C} 2 \mathrm{H} 2)$ and more than two fingers per molecule. All appear to be regulators of gene expression and to interact with DNA via the ' $\mathrm{Zn}$-finger' region. The precise structure adopted by these fingers and their mode of attachment to DNA is still subject to debate (Berg, 1988, 1990; Gibson et al. 1988). However, it seems likely that the 'fingers' contain both $\beta$-sheet and helical zones and interact with the major groove of DNA. Although TFIIIA functions as a transcription factor for RNA polymerase III, most of these proteins bind to promoters for RNA polymerase II (EC 2.7.7.6) and one of the most extensively studied of these, $\mathrm{Sp} 1$, is involved in the regulation of a wide range of genes. Sp1 binds to a 'GC box' in their promoters and has three contiguous finger sequences which require $\mathrm{Zn}$ and determine the specificity of attachment of Sp1 to DNA (Kadonaga et al. 1987; Westin \& Schaffner, 1988b). However, transcriptional activation by $\mathrm{Sp} 1$ appears to be mediated by regions of the protein outwith the ' $\mathrm{Zn}$-finger' zone. Although the mechanism by which binding of Sp1 promotes the transcription of respon- 
sive genes is unknown, it does not enhance binding of transcription factor IID to the TATA box (Schmidt et al. 1989).

The second group of 'finger' proteins comprise a range of receptors for thyroxine and many steroid hormones. Superficially similar to the $\mathrm{C} 2 \mathrm{H} 2$ proteins, their functionality is relatively independent of the position of their receptor sequence within its promoter, they always have only two fingers in each of which $\mathrm{Zn}$ is tetrahedrally coordinated to four cysteines (C4) and all contain an extra cysteine at the C-terminal finger (Sunderman \& Barber, 1988). Furthermore, the number of amino acids separating the central cysteines of each finger is constant within the group but is not the same for the two fingers. The $\mathrm{N}$-terminal 'loop' contains thirteen and the other finger nine or twelve depending on which pair of the terminal group of three cysteines is actually involved in the chelation of $\mathrm{Zn}$. These proteins appear to have three functional zones. Chimeric proteins constructed by molecular biological techniques clearly demonstrated that the specificity for hormone recognition depends on a hormone binding site in the $\mathrm{C}$-terminal region of the proteins. However, gene activation or repression seems to be mediated by the $\mathrm{N}$-terminal domain while the central region contains the ' $\mathrm{Zn}$ fingers' required for binding to the promoter. Mutational analysis of the 'Zn-finger' regions has led to a number of conclusions (Umesono \& Evans, 1989). It appears that the amino acids in the 'loops' between the central cysteines of each finger are required for binding to DNA but do not determine the specificity of this binding since they can be interchanged between different hormone receptors without alteration to the sequences recognized. These sequences, hormoneresponsive elements (HRE), are generally palindromes consisting of two hexanucleotides (Fig. 1). The hormonal specificity of the HRE is partly determined by their hexanucleotide sequences but also depends on their separation. Thus, the oestrogen (ERE)- and thyroid (TRE)-receptor palindromes are identical but in the ERE the two halves are separated by three nucleotides whereas in the TRE they are contiguous. Further mutational analysis has indicated that the specificity of hormone-receptor binding depends on the two amino acids separating the pair of $\mathrm{Zn}$-binding cysteines on the C-terminal side of the first 'finger' and on the next two or three amino acids immediately adjacent to the final cysteine of this 'finger'. These amino acids seem to determine palindrome sequence recognition while a second group of amino acids situated between the $\mathrm{N}$-terminal pair of cysteines in the second 'finger' may be involved in determining specificity associated with the distance between the two halves of the palindrome.

The final group are all transcription factors from fungi and contain a sequence of twenty-seven amino acids with six cysteines in highly conserved locations (Tao \& Coleman, 1990). These proteins require $\mathrm{Zn}$ for DNA binding and were initially thought to be ' $\mathrm{Zn}$-finger' proteins but recent evidence indicates that the conserved structures contain two $\mathrm{Zn}$ ions in a cluster of six cysteines two of which are coordinated with both $\mathrm{Zn}$ ions. These proteins are, thus, more reminiscent of the structure of metallothionein than that of the ' $\mathrm{Zn}$-finger' proteins.

\section{ZN AND GENE EXPRESSION}

Many $\mathrm{Zn}$ enzymes have been investigated in the past but so far no clear relationship has emerged between their activity and onset of growth failure associated with dietary $\mathrm{Zn}$ 
(a)

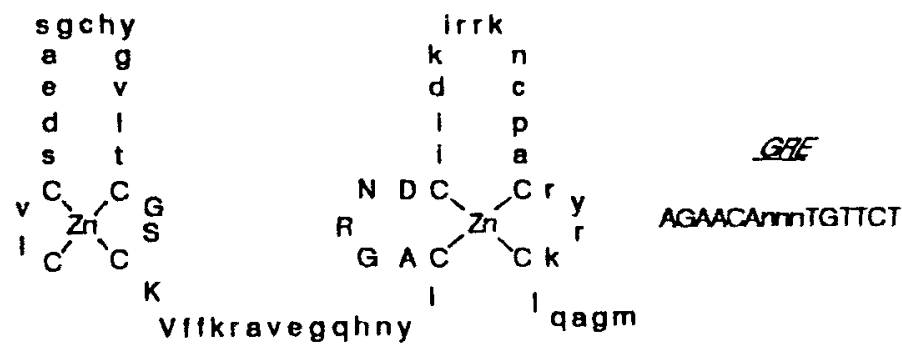

(b)
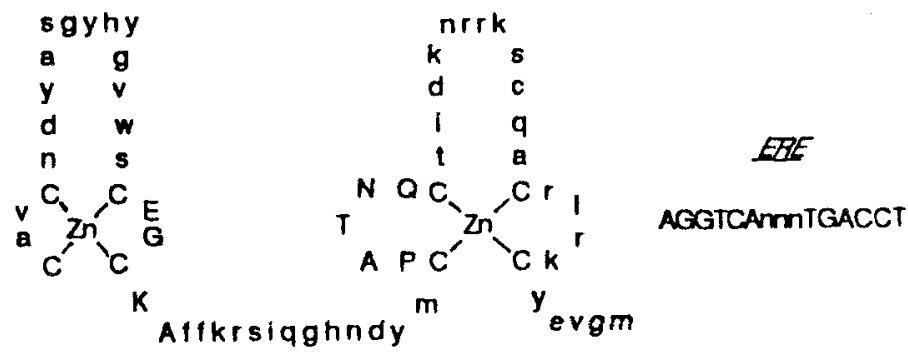

(c)
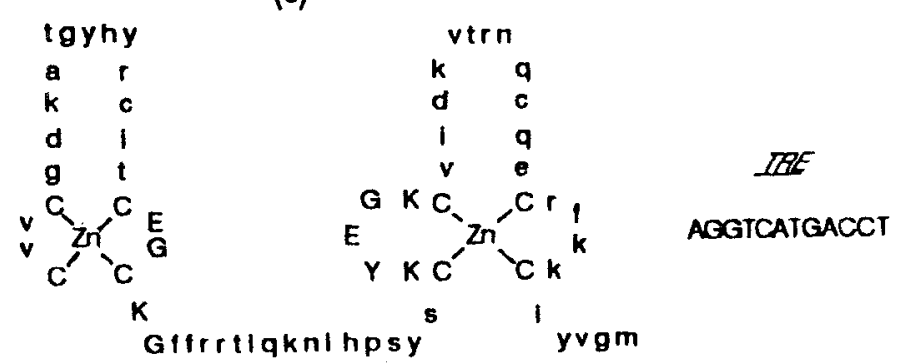

Fig. 1. Amino acid sequence of the 'zinc fingers' and nucleotide sequence of the hormone-responsive elements for (a) glucocorticoid (GRE), (b) oestrogen (ERE), and (c) thyroid (TRE) hormones. Amino acids involved in $\mathrm{Zn}$ binding or in determining hormonal specificity are shown in capital letters. In the nucleotide sequences, $n$ indicates a non-conserved base. Based on Umesono \& Evans (1989).

deficiency. Instead, the studies which will be reviewed suggest that $\mathrm{Zn}$ may be required for alterations in the expression of certain genes (Chesters, 1978).

Both in rats and in cell cultures in which $\mathrm{Zn}$ availability has been restricted by addition of a chelator, DNA synthesis is more sensitive to lack of $\mathrm{Zn}$ than is protein synthesis (Williams \& Chesters, 1970; Chesters, 1978). Early investigations demonstrated that reduced thymidine incorporation caused by $\mathrm{Zn}$ deficiency was associated with lower thymidine kinase (EC 2.7.1.21) activity in cultures (Lieberman et al. 1963), in rat fetuses (Duncan \& Hurley, 1978), and in wound-healing experiments (Prasad, 1982). However, there appears to be no evidence that thymidine kinase contains $\mathrm{Zn}$; in both the fetus and in culture, DNA polymerase activity was also reduced to a comparable extent (Lieberman et al. 1963; Duncan \& Hurley, 1978) and the reduction in these enzyme 
Table 1. Effect of zinc deficiency on the Zn content and growth characteristics of the buccal mucosa of the rabbit (based on Chen (1986))

\begin{tabular}{lcc}
\hline \hline Zn status $\ldots$ & Zn-deficient & Zn-adequate \\
\hline Zn concentration $(\mu \mathrm{g} / \mathrm{g}$ protein) & 167 & 265 \\
Mitotic index & $1 \cdot 31$ & $0 \cdot 89$ \\
Cell cycle time $(\mathrm{h})$ & $21 \cdot 0$ & 31.7 \\
$\mathrm{G}_{1}$ transit time $(\mathrm{h})$ & 16.8 & 26.8 \\
\hline
\end{tabular}

activities was proportional to the reduction in the number of cells labelled with thymidine (Fujioka \& Lieberman, 1964). Taken together, these findings point to a failure of individual cells to induce the block of enzymes required for DNA synthesis rather than a generalized reduction in activity of enzymes requiring $\mathrm{Zn}$ for their catalytic activity or structural integrity. Recent studies of $3 \mathrm{~T} 3$ cells stimulated from quiescence have indicated that for normal initiation of DNA synthesis, $\mathrm{Zn}$ is required for only a short period immediately preceding the induction of the enzymes needed for DNA synthesis (Chesters et al. 1989) and that the normal rise in thymidine kinase mRNA was substantially and specifically reduced in the absence of adequate $\mathrm{Zn} \mathrm{(J.} \mathrm{K.} \mathrm{Chesters} \mathrm{and}$ L. Petrie, unpublished results). These observations reinforce the suggestion that lack of $\mathrm{Zn}$ inhibits the induction of the enzymes required for DNA synthesis.

Although in most tissues and in culture, DNA synthesis and cell division appear to be inhibited by $\mathrm{Zn}$ deficiency, in the buccal mucosa it results in elevated rates of cell division and in impaired differentiation of the cells as they mature (Chen, 1986; Table 1). In the rat fetus, even transient reductions in $\mathrm{Zn}$ supply during the critical period for tissue differentiation have been shown to result in substantially increased incidence of fetal abnormalities (Record et al. 1985). Both these observations are consistent with a role for $\mathrm{Zn}$ in changes in genetic expression during differentiation, the effects on entry into $\mathrm{S}$ phase being only a prime example of the need for $\mathrm{Zn}$ in gene activation. If this suggestion has wider validity, one might expect that various other differentiation processes, including some not involving DNA synthesis, would also be dependent on Zn supply. Interestingly, recent studies of myoblast differentiation, a process initiated only after the cells have left the replication cycle (Florini \& Magri, 1989), indicated that increase in both creatine kinase ( $E C$ 2.7.3.2) mRNA and activity was inhibited in the absence of adequate $\mathrm{Zn}$ (L. Petrie and J. K. Chesters, unpublished results).

The previously described observations are consistent with a role for $\mathrm{Zn}$ in the regulation of transcription of a number of important genes. This raises the question of whether the crucial role of $\mathrm{Zn}$ may relate to one or more of the ' $\mathrm{Zn}$-finger' proteins since these have been shown to perform just this type of function. Following reports of $\mathrm{Zn}$ in TFIIIA, its functional adequacy was assessed both in EDTA-treated cultures and in Zn-deficient rats (Chesters et al. 1988). 5S rRNA synthesis was found to be impaired in the cultures but not in the rats. This was thought to be due to a relatively high affinity for $\mathrm{Zn}$ inherent in its tetrahedral coordination by two cysteine and two histidine residues. It seemed that this structure was sensitive to the strong chelator but could retain $\mathrm{Zn}$ with sufficient tenacity to prevent its loss following the relatively slight reduction in $\mathrm{Zn}$ availability which occurs with dietary $\mathrm{Zn}$ deficiency. However, a recent report has indicated that the dissociation constant for $\mathrm{Zn}$ of a synthetic ' $\mathrm{Zn}$-finger' peptide is of the 
order of $10^{-9} \mathrm{M}$ (Berg \& Merkle, 1989) which is close to the best estimates available for the concentration of free $\mathrm{Zn}^{2+}$ in serum (May et al. 1977; Magneson et al. 1987). This suggests that even in an animal, some 'finger' proteins may not be fully saturated with $\mathrm{Zn}$. Variations in amino acid sequence around the $\mathrm{Zn}$-binding sites may have resulted in transcription factors with a lower affinity for $\mathrm{Zn}$ than that of TFIIIA and with an ability to retain $\mathrm{Zn}$ and bind to DNA that may be adversely affected by dietary $\mathrm{Zn}$ deficiency. It is exciting to postulate that after years of investigation since dietary $\mathrm{Zn}$ deficiency was first recognized, the basic function of this element in controlling growth may be in sight.

\section{REFERENCES}

Berg, J. M. (1988). Proposed structure for the Zn-binding domains from transcription factor IIIA and related proteins. Proceedings of the National Academy of Sciences 85, 99-102.

Berg, J. M. (1990). Zinc fingers and other metal-binding domains - Elements for interactions between macromolecules. Journal of Biological Chemistry, 265, 6513-6516.

Berg, J. M. \& Merkle, D. L. (1989). On the metal ion specificity of zinc finger proteins. Journal of the American Chemical Society 111, 3759-3761.

Chambers, I. \& Harrison, P. R. (1987). A new puzzle in selenoprotein biosynthesis: selenocysteine seems to be encoded by a stop codon UGA. Trends in Biochemical Science 12, 255-256.

Chen, S.-Y. (1986). Autoradiographic study of cell proliferation in acanthotic buccal epithelium of $\mathrm{Zn-deficient}$ rabbits. Archives of Oral Biology 31, 535-539.

Chesters, J. K. (1978). Biochemical functions of zinc in animals. World Reviews of Nutrition and Dietetics 32, $135-164$.

Chesters, J. K., Petrie, L., Boyne, R. \& Allen, G. (1988). The role of zinc in regulating ribosomal RNA synthesis in vivo and in vitro. Joumal of Trace Elements in Experimental Medicine 1, 117-127.

Chesters, J. K., Petrie, L. \& Vint, H. (1989). Specificity and timing of the $\mathrm{Zn}^{2+}$ requirement for DNA synthesis by 3 T3 cells. Experimental Cell Research $\mathbf{1 8 4}, 499-508$.

Danks, D. M. \& Mercer, J. F. B. (1988). Metallothionein and ceruloplasmin genes. In Trace Elements in Man and Animals-6, pp. 287-291 [L. S. Hurley, C. L. Keen, B. Lonnerdal and R. B. Rucker, editors]. New York: Plenum Press.

Duncan, J. R. \& Hurley, L. S. (1978). Thymidine kinase and DNA polymerase activity in normal and $\mathrm{Zn}$-deficient developing rat embryos. Proceedings of the Society of Experimental Biology and Medicine 159, 39-43.

Evans, R. M. \& Hollenberg, S. M. (1988). Zinc fingers: gilt by association. Cell 52, 1-3.

Evans, G. W., Majors, P. F. \& Cornatzer, W. E. (1970). Induction of ceruloplasmin synthesis by copper. Biochemical and Biophysical Research Communications 41, 1120-1125.

Florini, J, R. \& Magri, K. A. (1989). Effects of growth factors on myogenic differentiation. American Journal of Physiology 256, C701-C711.

Fujioka, M. \& Lieberman, I. (1964). A $\mathrm{Zn}^{2+}$ requirement for synthesis of deoxyribonucleic acid by rat liver. Journal of Biological Chemistry 239, 1164-1167.

Garg, L. C., Dixit, A., Webb, M. L. \& Jacob, S. T. (1989). Interaction of a positive regulatory factor(s) with a 106 bp upstream region controlling transcription of metallothionein-1 gene in the liver. Journal of Biological Chemistry 264, 2134-2138.

Gibson, T. J., Postma, J. P. M., Brown, R. S. \& Argos, P. (1988). A model for the tertiary structure of the 28 residue DNA-binding motif ('zinc finger') common to many eukaryotic transcriptional regulatory proteins. Protein Engineering 2, 209-218.

Hanas, J. S., Hazuda, D. J., Bogenhagen, D. F., Wu, F. Y.-H. \& Wu, C.-W. (1983). Xenopus transcription factor A requires $\mathrm{Zn}$ for binding to the 5S RNA gene. Journal of Biological Chemistry 258, 14120-14125.

Harris, E. D. \& Stevens, M. D. (1985). Receptors for ceruloplasmin in aortic cell membranes. In Trace Elements in Animals and Man, pp. 320-323 [C. F. Mills, I. Bremner and J. K. Chesters, editors]. Slough: Commonwealth Agricultural Bureaux.

Kadonaga, J. T., Carner, K. R., Masiarz, F. F. \& Tjian, R. (1987). Isolation of cDNA encoding transcription factor Sp1 and functional analysis of the DNA binding domain. Cell 51, 1079-1090.

Klausner, R. D. \& Harford, J. B. (1989). Cis-trans models for post-transcriptional gene regulation. Science 246, $870-872$. 
Klug, A. \& Rhodes, D. (1987). Zinc fingers: a novel protein motif for nucleic acid recognition. Trends in Biochemical Science 12, 464-469.

Leinfelder, W., Forschhammer, K., Verprek, B., Zehelein, E. \& Bock, A. (1990). In vitro synthesis of selenocysteine-tRNAuca from seryl-tRNAuca: involvement and characteristics of the selD gene product. Proceedings of the National Academy of Sciences 87, 543-547.

Li, N.-Q., Reddy, P. S., Thyagaraju, K., Reddy, A. P., Hsu, B. L., Scholz, R. W., Tu, C.-P. D. \& Reddy, C. C. (1990). Elevation of rat liver mRNA for Se-dependent glutathione peroxidase by selenium deficiency. Journal of Biological Chemistry 265, 108-113.

Lieberman, I., Abrams, R., Hunt, N. \& Ove, P. (1963). Levels of enzyme activity and deoxyribonucleic acid synthesis in mammalian cells cultured from the animal. Journal of Biological Chemistry 238, 3955-3962.

Magneson, G. R., Puvathingal, J. M. \& Ray, W. J. (1987). The concentrations of free $\mathrm{Mg}^{2+}$ and free $\mathrm{Zn}^{2+}$ in equine blood plasma. Journal of Biological Chemistry 262, 1.140-1148.

May, P. M., Linder, P. W. \& Williams, D. R. (1977). Computer simulation of metal-ion equilibria in biofluids: models for the low molecular weight complex distribution of $\mathrm{Ca}$ (II) $\mathrm{Mg}$ (II) $\mathrm{Mn}$ (II) $\mathrm{Fe}$ (II) $\mathrm{Cu}$ (II) $\mathrm{Zn}$ (II) and $\mathrm{Pb}$ (II) ions in human blood plasma. Journal of Chemical Society (1977), 588-595.

Prasad, A. S. (1982). Zinc deficiency in human subjects. In Clinical, Biochemical and Nutritional Aspects of Trace Elements, pp. 3-62 [A. S. Prasad, editor]. New York: A. R. Liss.

Record, I. R., Dreosti, I. E., Tulsi, R. S. \& Manuel, S. J. (1985). Maternal metabolism and teratogenicity in Zn-deficient rats. Teratology 33, 311-317.

Saedi, M. S., Smith, C. G., Frampton, J., Chambers, I., Harrison, P. R. \& Sunde, R. A. (1988). Effect of selenium status on mRNA levels for glutathione peroxidase in rat liver. Biochemical Biophysical Research Communications 153, 855-861.

Schmidt, M. C., Zhou, Q. \& Berk, A. J. (1989). Sp1 activates transcription without enhancing DNA-binding activity of the TATA box factor. Molecular and Cellular Biology 9, 3299-3307.

Seguin, C., Felber, B. K., Carter, A. D. \& Hamer, D. H. (1984). Competition for cellular factors that activate metallothionein gene transcription. Nature 312, 781-785.

Seguin, C. \& Prevost, J. (1988). Detection of a nuclear protein that interacts with a metal regulated element of the mouse metallothionein-1 gene. Nucleic Acid Research 16, 10547-10560.

Stuart, G. W., Searle, P. F., Chen, H. Y., Brinster, R. L. \& Palmiter, R. D. (1984). A 12 base-pair DNA motif that is repeated several times in metallothionein gene promoters confers metal regulation to a heterologous gene. Proceedings of the National Academy of Sciences 81, 7318-7322.

Sunderman, F. W. \& Barber, A. M. (1988). Finger-loops, oncogenes, and metals. Annals of Clinical and Laboratory Science 18, 267-288.

Tao, P. \& Coleman, J. E. (1990). Gal4 transcription factor is not a zinc finger but forms a Zn(II)2Cys6 binuclear cluster. Proceedings of the National Academy of Sciences 87, 2077-2081.

Toyoda, H., Himeno, S. \& Imura, N. (1989). The regulation of glutathione peroxidase gene expression; implications for species differences and the effect of dietary selenium manipulation. In Selenium in Biology and Medicine, pp. 3-7 [A. Wendel, editor]. Berlin: Springer Verlag.

Umesono, K. \& Evans, R. M. (1989). Determinants of target gene specificity for steroid/thyroid hormone receptors. Cell 57, 1139-1146.

Westin, G. \& Schaffner, W. (1988a). A zinc-responsive factor interacts with a metal-regulated enhancer element (MRE) of the mouse metallothionein-1 gene. EMBO Journal 7, 3763-3770.

Westin, G. \& Schaffner, W. (1988b). Heavy metal ions in transcription factors from HeLa cells; Sp1, but not octamer transcription factor requires zinc for DNA binding and for activator function. Nucleic Acids Research 16, 5771-5781.

Williams, R. B. \& Chesters, J. K. (1970). The effects of early zinc deficiency on DNA synthesis and protein synthesis in the rat. British Journal of Nutrition 24, 1053-1059. 